Article

\title{
Emerging Diffusion Barriers of Shared Mobility Services in Korea
}

\author{
Sungwon Kim ${ }^{1}$, Hwansoo Lee ${ }^{2, *}$ (1) and Seung-Woo Son ${ }^{3, *}$
}

1 Department of IT Law, Dankook University, Yongin-si 16890, Korea; redmoon357@gmail.com

2 Department of Industrial Security, Dankook University, Yongin-si 16890, Korea

3 Department of Industrial Security, Chung-Ang University, Seoul 06974, Korea

* Correspondence: hanslee992@gmail.com (H.L.); legalssw@gmail.com (S.-W.S.)

+ This work is an extended version of an author's own referenced conference article published in 2020 International Conference on Artificial Intelligence in Information and Communication (ICAIIC), Fukuoka, Japan, 19-21 February 2020.

Citation: Kim, S.; Lee, H.; Son, S.-W. Emerging Diffusion Barriers of Shared Mobility Services in Korea . Sustainability 2021, 13, 7707. https:// doi.org/10.3390/su13147707

Academic Editors: Adam Torok and Luigi Aldieri

Received: 7 April 2021

Accepted: 6 July 2021

Published: 9 July 2021

Publisher's Note: MDPI stays neutral with regard to jurisdictional claims in published maps and institutional affiliations.

Copyright: (c) 2021 by the authors. Licensee MDPI, Basel, Switzerland. This article is an open access article distributed under the terms and conditions of the Creative Commons Attribution (CC BY) license (https:// creativecommons.org/licenses/by/ $4.0 /)$.
Abstract: Korea's shared mobility service, TADA, has been accused of violating the Passenger Transportation Services Act, despite being an innovative transportation service. A key reason for this is that TADA is yet to discover an approach to coexist with traditional transportation service companies. The TADA case shows that in addition to technical or business matters, a variety of issues can act as new barriers to the spread of innovation. Therefore, this study aims to understand the emerging barriers that need to be addressed in adopting breakthrough technologies, particularly for shared mobility services. The purpose of this study is to show that the introduction of innovative technology encounters not only technological barriers, as suggested in previous research, but also political, industrial, and legal barriers to diffusion that hinder innovation. Therefore, this study applied the text mining method to online news big data to confirm the existence of diffusion barriers for shared mobility services. The results demonstrate that not only technical efforts but also discussions with various stakeholders and efforts to minimize industrial and legal resistance are required to effectively spread innovative services.

Keywords: shared mobility service; innovation diffusion; barrier; text-mining; TADA

\section{Introduction}

The entry into the Fourth Industrial Revolution caused rapid changes in various industries [1]. These changes appeared in the field of transportation, and the sharing economy-based ride sharing service emerged [2]. In particular, the development of big data and artificial intelligence technology contributed to the advancement of mobility services. As a result, various shared mobility services such as Uber began to be launched competitively. In line with these changes in Korea, artificial intelligence-based shared mobility services such as "Kakao Taxi" and "TADA" have appeared. These innovative mobility services were expected to contribute to improving the convenience and efficiency of transportation for citizens [3].

Although in Korea, the Fourth Industrial Revolution and information and communications technology (ICT) innovations are rapidly emerging, shared mobility services such as TADA have been legally problematic. According to the Korean Passenger Transport Service Act [4], rental vehicles such as ride-hailing vans cannot operate until rented to passengers. In addition, mobility service providers are struggling to launch their services owing to strong opposition from the rival taxi industry. As a result, it has become a social issue as the interests of the taxi industry and the ride-hailing companies collide. New mobility services such as TADA are illegal in Korea and constitute a case of innovation failure due to conflicts with the taxi industry, which is concerned with job security, lack of laws, and the spread of social awareness. Conversely, California began legalizing Uber services in 2013, 2014, and 
2015; Colorado and New York also joined in the legalization of Uber [5]. In Australia, Uber has been legalized since 2015; however, in Korea, TADA became illegal, and the existing service was suspended. In Korea, Uber was illegally operated and withdrawn in 2015. Therefore, it is necessary to examine whether the withdrawal of shared mobile service was caused by different legal standards or for other reasons. The factors influencing the failure of innovative services must be examined, focusing on the TADA service in Korea, where innovative services have been continuously withdrawn.

Existing studies related to the Fourth Industrial Revolution have focused mainly on the technology itself or on the business effects. There is barely any discussion of the various types of resistance or barriers that these technological innovations can face. Because fostering new industries based on innovative technologies is directly connected to the future growth and development of the country, it is important to minimize resistance to new technologies at the national level so that they can be utilized in various forms [6]. In the case of shared mobility services, they are attracting attention because they can affect the construction of smart cities and the development of the smart tourism industry $[7,8]$. However, given the situation in Korea, where there have been discussions concerning the illegal operation and permanent ban of TADA services due to various forms of resistance, it is now necessary to actively discuss resistance factors as non-technical factors. Solving these issues requires academic discourse on barriers to innovation. Based on the theory of barriers to innovation, which can aid in understanding resistance to the acceptance of innovative technologies, it is possible to see what social perspectives the emerging technologies should consider.

\section{Research Question: What are the new types of innovation barriers besides technological} barriers?

For the research question, this study discusses the innovation barriers that should be considered by innovative technologies, with a focus on TADA services. This study conducted a "big data" analysis to examine how people perceive the TADA service and systematized resistance factors through keyword analysis. Because most of the existing studies have analyzed resistance to technology diffusion mainly from the viewpoint of the technology itself or users, only limited discussions of resistance to technology were possible. In addition, although some studies have conducted comprehensive discussions on technology barriers, they were limited to qualitative studies. Thus, there was a limit to the generalizations that could be made regarding barriers to the spread of new technologies through empirical analysis. As this study attempted a new approach through online big data analysis to overcome the limitations of existing studies, the results will contribute to understanding the barriers to new perspectives on technological innovation.

The remainder of this paper is organized as follows. In Section 2, we review the existing literature on shared mobility and innovation barriers. In Section 3, we introduce the research procedure and methodology. In Section 4, we present the results of the big data analysis using the text mining technique. Finally, we discuss the results of the analysis and conclude the paper in Section 5.

\section{Related Background}

\subsection{Sharing Economy and Shared Mobility Services}

With the development of digital technology, the sharing economy is emerging as a new economic paradigm. The sharing economy is the concept of maximizing the utilization of idle resources by sharing products with many people [9]. The global sharing economy market has grown rapidly, and the world is paying attention to its potential value and development. According to PricewaterhouseCoopers (PWC), the market size of the sharing economy is expected to reach $\$ 335$ billion by 2025 . The sharing of tangible resources such as cars, spaces, clothing, and books emerged earlier and has gradually been expanding to the sharing of intangible resources such as time and talent, used goods, rental products, office space, lodging, finance, and transportation [10] (Table 1). 
Table 1. Sharing Economy Services.

\begin{tabular}{|c|c|c|c|}
\hline \multirow{2}{*}{ Category } & \multirow{2}{*}{ Shared Resource } & \multicolumn{2}{|c|}{ Companies } \\
\hline & & Korea & Global \\
\hline \multirow[t]{2}{*}{ Traffic } & & $\begin{array}{l}\text { TADA, Kakao T, SOCAR, Udigo, } \\
\text { GreenCar, Poolus }\end{array}$ & UBER, ZipCar \\
\hline & Bicycles & Kakao T bike, PurunBike & Velib, Barclay Cycle Hire \\
\hline \multirow[t]{2}{*}{ Goods } & Used goods & $\begin{array}{c}\text { Auction, } \\
\text { G market, } \\
11 \text { st }\end{array}$ & Ebay, Craigslist, Flippid \\
\hline & Rental products & $\begin{array}{l}\text { Libpia, } \\
\text { The Shared Library }\end{array}$ & Chegg, Zookal \\
\hline \multirow{2}{*}{ Space } & Office space & WeWork & Sharedspace \\
\hline & Accommodation & Kozaza & AirBnB \\
\hline Finance & Crowdfunding & Popfunding, Ssiatfunding & Kickstarter, Indiegogo \\
\hline
\end{tabular}

The rapid development of ICT has further accelerated the spread of the sharing economy. Social networking, big data, artificial intelligence, and cloud computing technologies have contributed to making sharing between people simpler. Digital platforms have also played an important role in revitalizing the sharing economy. Digital platforms have created a new form of transaction called the platform economy by allowing suppliers and consumers to efficiently trade directly through digital devices. This has improved the possibility of realizing the sharing economy with high accessibility and low cost [11]. As ICT-enabled shared services provide affordability, accessibility, convenience, ease-of-use, and enjoyment, many people prefer the services, and the related industries are steadily growing.

Sharing economy services have various advantages and disadvantages. Advantages include economic benefits that improve efficiency through the use of idle resources and non-economic benefits such as the improvement of environmental problems. In the sharing economy, business expansion is straightforward because transactions are conducted through an online platform. Moreover, the sharing economy has significant incentive to revitalize and discover new industries as it provides consumers with reasonable cost and high accessibility through an innovative business model that did not previously exist [12]. Conversely, resistance to new service concepts, illegalities associated with the sharing economy model, negative perceptions of shared objects used by others, the potential for invasion of privacy, and service quality assurance are key issues to be resolved [13].

Interest in the sharing economy has had great influence on the emergence of mobility services. Various shared mobility services have begun to appear, and are attracting attention as innovative services through the use of Fourth Industrial Revolution technologies (e.g., blockchain, internet of things (IoT), AI) [14]. For example, the convergence of IT and mobility has led to the development of E-hailing services that provide a variety of forms of transport. In fact, various shared mobility services have evolved as shown in Table 2, and new services such as "TADA" have grown in popularity with other shared mobility services. The definitions of new shared mobility services are actively emerging, so the classification is also changing according to the service innovation.

Shared mobility services can be divided into three types. First, ride-hailing (RH) is a service that calls local drivers through smart applications. This is similar to the existing calltaxi service. Second, ridesharing (RS) refers to a service where people sharing a destination connect to each other through a smart application to share the ride to their destination [15]. Carpooling is also included in the RS service. RS mainly uses privately owned vehicles or company sales vehicles registered in the related application. Third, car-sharing (CS) is a service for renting a vehicle for a short period of time through an application for the purpose of sharing the use of the vehicle with an unspecified number of people. 
Table 2. Types of Shared Mobility Service.

\begin{tabular}{cl}
\hline Classification & \multicolumn{1}{c}{ Features } \\
\hline $\begin{array}{c}\text { Ride-Hailing } \\
\text { (Car Hailing) }\end{array}$ & $\begin{array}{l}\text { Connecting services to local taxi driver } \\
\text { Like a call taxi system }\end{array}$ \\
\hline \multirow{2}{*}{ Ride-Sharing (RS) } & $\begin{array}{l}\text { Connecting services to enrolled drivers (or company that owns } \\
\text { automobiles or enrolls people for driving) } \\
\end{array}$ \\
& Able to carpool with other passengers (carpooling) \\
& Drivers have their own vehicles \\
\hline Car-Sharing & Connecting services to enrolled driver or company driver \\
(CS) & Commonly uses vehicles leased by the company \\
& Sharing service for automobiles (like a short-term car lease) \\
\hline
\end{tabular}

In existing research, RS and CS are classified as similar or identical concepts, but there is a distinct conceptual difference. RS is a service in which the vehicle driver (often, the vehicle's owner) and passengers sharing a similar destination share the "boarding" of the vehicle and the "movement" of the route. In a CS scheme, the use of the vehicle itself is shared among users. RS is a service that arranges connections between drivers and passengers who mainly "share destinations". Conversely, CS is more of a rental service in the dimension of "sharing vehicles" to achieve a specific purpose rather than sharing destinations and boarding. In addition, services newly defined as a combination of services, such as microtransit, are not classified as separate services due to their strong similarity to $\mathrm{RH}$. Shared mobility service providers are presented in Table 3 . These companies have adopted the different types of business models shown in Table 2 in parallel or individually.

\subsection{Traditional Innovation Barriers}

New services or innovative technologies inevitably face resistance from existing market players. Various types of risk, such as personal, social, economic, or political risks, influence resistance to innovation [8]. Conventionally, the resistance to breakthrough technologies has been studied with a focus on psychological factors in personal or social networks, such as habit formation based on the use of the existing technology or social pressure associated with being "different from others".

Personal barriers to innovative technologies can take many forms. A usage barrier refers to an avoidance of the changes caused by the use of new technology [16]. As mentioned above, users often have fixed habits according to social practices or individual tendencies. Sheth [17] and Ram [18] have argued that when new technologies bring about changes to familiar patterns, individuals are inclined to resist them to maintain the status quo. In other words, when the habits or life patterns of users are not taken into account when developing innovative technology that may bring substantial changes into the lives of users [19], it becomes a barrier in their attempts to use the technology and may even thwart those attempts [20,21]. Individual technological competence of potential users also influences the acceptance of innovative technology, is one of the determinants motivating individuals to take certain actions, and is referred to as "self-efficacy" [22] Those who have learned to easily accept technological changes or have a high interest in and adaptability to breakthrough technologies, whether by nature or nurture, are more at ease with innovative technologies. In contrast, those who are not exposed to breakthrough technologies, have few opportunities to learn, or are not familiar with technological aspects for other reasons, including age or a lower sense of self-efficacy, are more likely to resist technological changes [23]. 
Table 3. Features of Shared Mobility Services.

\begin{tabular}{|c|c|c|}
\hline \multicolumn{2}{|c|}{ Classification } & \multirow{2}{*}{$\begin{array}{l}\text { Features } \\
\text { Linked with internal taxi platform } \\
\text { Uses stabilized taxi terminals and payment system }\end{array}$} \\
\hline Arro & $\mathrm{RH}$ & \\
\hline BlaBlaCar & RS & $\begin{array}{l}\text { Drivers can determine who rides with them } \\
\text { Operation of a detailed classification system for driver's preferences } \\
\text { Exclusive options for female drivers }\end{array}$ \\
\hline Bridj & $\mathrm{RH}$ & $\begin{array}{l}\text { Utilizes public transportation routes (bus) } \\
\text { Operates around a pick-up point } \\
\text { Special access for people with physical challenges }\end{array}$ \\
\hline Cabify & RS & $\begin{array}{l}\text { Passengers can choose trip preferences } \\
\text { Option to reserve or schedule a ride }\end{array}$ \\
\hline Curb & RH & $\begin{array}{l}\text { Utilizes existing taxi drivers } \\
\text { Requires drivers to have insurance } \\
\text { Provides reservation and tracking for vehicles }\end{array}$ \\
\hline $\begin{array}{l}\text { Didi } \\
\text { Chuxing }\end{array}$ & $\mathrm{RS} / \mathrm{RH} / \mathrm{CS}$ & $\begin{array}{l}\text { Collaborates with the taxi industry } \\
\text { Offers a variety of service options (taxi-hailing or ridesharing in a } \\
\text { personal vehicle or a rental company's car) } \\
\text { Services can be provided in conjunction with corporate platforms } \\
\text { such as Tencent or Alibaba }\end{array}$ \\
\hline Flywheel & RH & $\begin{array}{l}\text { Linked with taxi service platform } \\
\text { Separate payment system from taxi platform }\end{array}$ \\
\hline $\begin{array}{l}\text { Gett } \\
\& \\
\text { Juno }\end{array}$ & RS & $\begin{array}{l}\text { Drivers are required to have considerable driving expertise } \\
\text { Different payment systems based on region } \\
\text { Discounts for off-peak rides }\end{array}$ \\
\hline Gokid & RS & $\begin{array}{l}\text { Ride-sharing system for busy parents } \\
\text { Utilizes trust relationships, such as neighbors and coworkers } \\
\text { Journey tracking is available in real-time for parents } \\
\text { Works on mutual favors (no payment) }\end{array}$ \\
\hline Grab & RS & $\begin{array}{l}\text { Offers options using local public transportation } \\
\text { Real-time feedback on driver's experience }\end{array}$ \\
\hline Hitch & RS & $\begin{array}{l}\text { Drivers can post their schedule in advance } \\
\text { Ride reservation }\end{array}$ \\
\hline LYFT & RH & $\begin{array}{l}\text { Drivers must pass a background check } \\
\text { Passengers indicate satisfaction with the ride } \\
\text { Additional options available to reduce waiting time }\end{array}$ \\
\hline OLA & RS & $\begin{array}{l}\text { In affiliation with local transportation such as rickshaws in India } \\
\text { Provides real-time tracking of vehicle's driving path }\end{array}$ \\
\hline Uber & $\mathrm{RH}$ & $\begin{array}{l}\text { Expanded services beyond ridesharing } \\
\text { Active rating system for driver assessment } \\
\text { Available for people with pets } \\
\text { Option to add multiple drop-off points }\end{array}$ \\
\hline Via & RS & $\begin{array}{l}\text { If necessary, provides the driver with a vehicle rental } \\
\text { Can be linked to passengers on the same route }\end{array}$ \\
\hline Wingz & RS & $\begin{array}{l}\text { Passengers can book a trip up to two months ahead of time } \\
\text { Passengers can select their preferred driver directly } \\
\text { Flat rate costs (no hidden fees and surcharges) }\end{array}$ \\
\hline Ztrip & RS/CS & $\begin{array}{l}\text { Drivers can use their personal vehicle or a Ztrip rental } \\
\text { Ability to set customized pick-up vehicle setting }\end{array}$ \\
\hline
\end{tabular}


Factors that affect users' resistance to changes in technology can be divided into normative factors and psychological factors. Normative factors are represented by laws, rules, and customs and the pressure imposed on individuals to comply. Psychological factors arise from an individual's social network, including resistance caused by the image of breakthrough technologies. Previous studies have focused mostly on the psychological factors affecting the users of breakthrough technologies within the social environment of laws or traditions accepted in society (social norms). According to Kim and Kankanhali [23], social norms pressure individuals into adjusting their behavior to the norms, considering others' behavior, and comparing that behavior with their own. As a consequence, users are pressured into projecting themselves according to how the majority of people behave, which poses a social barrier to accepting a new innovative technology [21,24]. At the same time, the image of the new technology and the associated product, including its appearance, production origin, or producer, can be a factor affecting resistance [25]. In addition to personal preference (personal factor) for a product's appearance, social stereotypes, including negative perceptions or evaluations of the product or prototype, or a poor reputation of the manufacturer can affect the psychology of the individuals, creating a barrier to their acceptance of breakthrough technologies [26]. Privacy invasion caused by the use of new services can also be a factor for psychological resistance, and is likely to occur in the case of shared mobility [27].

Furthermore, the economic value or efficiency of innovative technologies can become a factor hampering acceptance. People tend to perceive the disadvantages of change as more significant than the advantages and thus have a preference for maintaining the status quo [28]. If the improvement in performance or convenience of a new technology, compared with the existing technology, is not cost-effective or efficient, users are not motivated to choose the new technology, thus posing an economic barrier to acceptance [29]. Meanwhile, many individuals fear losing their jobs due to the introduction of new technology. This is exemplified in the Luddite movement, in which English textile workers objected to the introduction of mechanized knitting frames for fear of losing jobs. It is believed that resistance from laborers delays the innovation process [30]. Businesses, too, fear losing their market share due to the introduction of breakthrough technologies and build barriers against them, especially when it is too costly or insurmountably difficult to replace their existing infrastructure with the new technology [30].

Uncertainty surrounding innovative technologies is another factor affecting users' status quo bias. These uncertainties include the possibility of malfunction or an added inconvenience in the process of adoption [18]. Negative perceptions about risks pose a barrier to the acceptance of new technologies [26,31] which, in turn, results in fear of learning new technologies [32]. The higher the perceived risks, the greater the resistance to change [18]. Therefore, uncertainty of risks can delay the adoption of breakthrough technologies until they are fully stabilized and accepted.

\subsection{Emerging Innovation Barriers}

The introduction of breakthrough technologies is often blocked for political reasons. A political barrier is one in which the main barrier is "political": for instance, when a political group opposes a new technology to protect its own interests. Often, interest groups are closely related to breakthrough technologies, both positively and negatively, and engage in lobbying or rent-seeking behavior in an attempt to protect or further their own interests. In the process, economic or political organizations are likely to be formed to control the decision-making process, and a "political marketplace" is likely to appear, disturbing the results of innovation [30]. To illustrate how this works, suppose there are two parties: Party A pushes forward with an "innovation policy," which Party B opposes; therefore, Party B confronts Party A. Each party has justifiable reasons to support their position, and it is difficult to distinguish which side is right or wrong. As the interest groups conflict with each other, it becomes increasingly difficult to revise laws, which consequently delays or derails the introduction of the technology in question. The political 
institutions and organizational structures of a country can also pose obstacles in adopting a new breakthrough technology. For instance, political organizations' tendencies to focus on responsibilities rather than on flexibility as well as to penalize failure and reward success insufficiently in innovation efforts serve as obstacles in adopting breakthrough technologies and contribute to maintaining the status quo [33].

The industrial structure that tries to introduce breakthrough technologies can also be a barrier. The high cost of the technological transfer, previously mentioned as an economic barrier, can also be discussed from the "industrial structure" viewpoint, but the structure here refers to that of the "labor-intensive" industry. Within democratic systems such as South Korea, large-scale industries with labor-intensive structures and limited automation are susceptible to political influences. Workers in these industries can raise their voices as voters to call for the protection of their jobs and businesses. Political groups, with the goal of gaining power for the next term, cannot ignore their constituents. Thus, a "labor-intensive" industrial structure hampers the discussion to introduce mechanization or automation. These political barriers mean that the spread of technology and the innovation process are obstructed for social reasons, rather than due to technological problems.

\subsection{Mobility Innovation Barriers: A Case Study of TADA}

TADA, Korea's ride-hailing service, provides an on-demand point-to-point transportation service that efficiently and automatically allocates vehicles closest to the destination requested by passengers using an AI-based dispatcher system (Figure 1) [34]. When a TADA user enters a destination in the mobile app, an AI-based dispatching system connects the nearest vehicle driver. By inhibiting the driver from knowing the user's destination until the user arrives, refusal to ride or discrimination against passengers was prevented. In addition, because users can check rates and routes that are updated in real time, the service can be used economically. Data requested from the Rider app and Driver app are delivered via the server to the Dispatcher for car allocation and the Tracker for collecting vehicle location information. Users and drivers are matched through the AI dispatch process while communicating with the database managing driving records and user data. In this process, the gRPC server handles real-time events, and Redis handles inter-server messaging (see Figure 1).

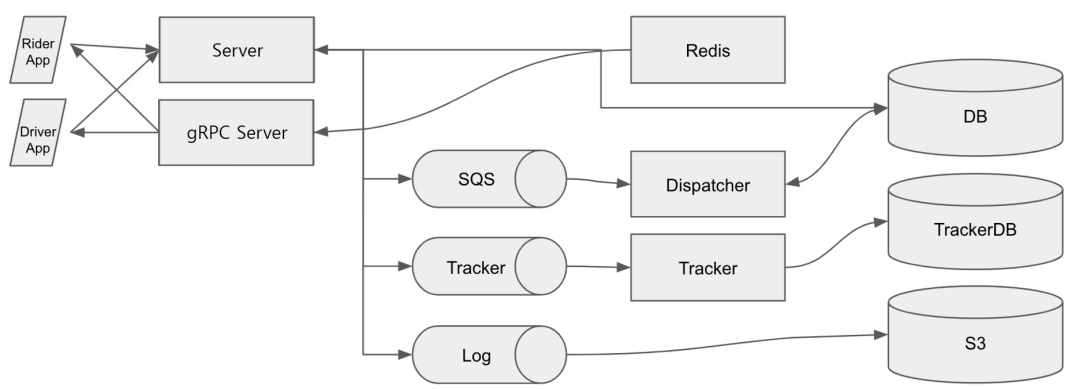

Figure 1. TADA's system architecture (https://engineering.vcnc.co.kr/2019/01/tada-systemarchitecture/, accessed on 7 April 2021).

Despite innovation in mobility services, legal regulations were an important issue to be resolved. Overseas shared mobility services are being freed from regulations for industrial development, whereas Korean services have been delayed due to legal, institutional, social, and political resistance despite having advanced related technologies [35]. The first problem was that early shared mobility services such as Uber violated Article 81 of the Passenger Transportation Service Act by using general vehicles rather than commercial vehicles for the services. Uber faced fierce opposition from the taxi industry and was finally forced to withdraw from the Korean market. Since then, various vehicle mobility service providers such as "Poolus", "LUXI", "Titicaca”, "Chacha”, "Udigo", "Kakao T”, 
"Socar", and "GreenCar" have appeared, including TADA. The service has been operated by utilizing an exception to Article 81 of the Act.

The Korean government considered that ride-hailing services could become a big market in the Fourth Industrial Revolution, and the government actively supported the development of related industries [36]. However, the taxi industry thought that ride-hailing services were a threat to their industry; thus, it began to oppose the establishment of ridehailing service companies for market protection [37]. From the taxi industry's point of view, the ride-hailing services are illegal, and their expansion will lead to unemployment of taxi drivers. On the other hand, ride-hailing service providers argued that their services are not illegal under current law and will not have a significant impact on the taxi industry. In addition, they argued that the ride-hailing service could not only solve problems of existing taxi service such as payment, service quality, and safety issues, but also create new demand in times when taxi supply is insufficient [37].

Under these circumstances, with members of each industry sharply divided due to differing interests and opinions, institutional and social conflicts have been on the rise. To make matters worse, political groups have intervened to strengthen their positions and ended up instigating conflicts. In Korea, the conflict between those in the shared mobility service industry and those who want to protect the existing taxi industry has become political. The double-edged problem of new technological introduction-which should be addressed through a social or industrial agreement-is becoming a political issue, over which the ruling and opposition parties, swayed by the coming election, fight to gain ground, fueling social conflicts. Some related groups, for their own interests, even argue that the election should be replaced by a referendum. This raises concerns over whether more important problems will be overshadowed by political disputes, without considering the failure of similar innovation attempts or the inconvenience to the public.

Significant effort was required to reach an agreement between the shared mobility and taxi industries. In March 2019, a major social compromise was made between the taxi industry and Kakao Mobility Service, allowing Kakao to operate the RH service only for $4 \mathrm{~h}$ on weekdays. However, because only Kakao Mobility Service participated in this negotiation process, the opinions of other RS service providers could not be presented. As a result, institutional and social conflicts did not significantly decrease; rather, controversy increased, and the political issue intensified.

Amid the ongoing conflict and confrontation, the court ruled in favor of TADA as a legitimate rental car service on 19 February 2020, in a landmark decision that is likely to uphold the shared mobility service industry. According to the ruling, the transaction between the passenger (user) and the car-sharing app SoCar on the TADA mobile platform as an ultra-short-term rental car contract is valid under the freedom of contract principle and should be granted a legal effect. Furthermore, it is considered a violation of the principle of legality to interpret the scope of licenses prescribed in the Passenger Transport Service Act, Article 34 Clause 3, which states that "No car rental business entity shall use any of his/her commercial motor vehicles for passenger transport to meet the needs of other persons." This includes the TADA service, which provides rental cars with a capacity of 11 to 15 seats to be legally leased with a driver, or any other multi-seater call taxi service, as it would be an extensive or analogical interpretation of the law beyond the possible meaning of the language.

With the court ruling, part of the legal barrier to shared mobility service appeared to crumble. The taxi industry, however, expressed dissatisfaction with the ruling and announced further action, indicating that social and emotional issues remain unresolved [38]. On 5 March 2020, as the revision (bill) on the "Passenger transport service act [No. 2022993]" was passed, TADA announced the termination of its service. The revision included the following points: removal of the provision of evidence based on which shared mobility services are allowed to operate; permission for rental cars to operate as platform transport businesses; and contributions from related industries [39]. TADA's initial service, which collided with the taxi industry, was eventually stopped. The service is currently operating; 
however, it has been altered such that it can only be used under certain circumstances that incur high cost. It is unclear how long the service can continue operating because its price competitiveness is now considerably weaker compared to the initial service.

\section{Method}

\subsection{Research Procedure and Data}

This study applied the text mining method to online news big data to confirm the existence of diffusion barriers to shared mobility services. The purpose of this study was to show that the introduction of innovative technology not only faces technological barriers, as suggested in previous research, but also political, industrial, and legal barriers to diffusion that can hinder innovation. By expanding the category of traditional diffusion barriers, it is possible to contribute to resolving the social conflict that has emerged with the introduction of innovative technologies. This study analyzed big data from the news pages of Korea's portal websites. TEXTOM (www.textom.co.kr accessed on 17 November 2019) service was used for data collection. UCINET6 and Netdraw were used for network analysis and data visualization. Eleven months of text data (1 January 2019-24 November 2019), including TADA as the keyword, were extracted from the news from Korea's portal websites such as Naver and Daum. As a result, a total of 44,257 words were extracted from 1513 webpages. The meaningless words among the extracted words were filtered and used for the final analysis. The research procedure is shown in Figure 2.

Research Question (Barrier Existence Online)
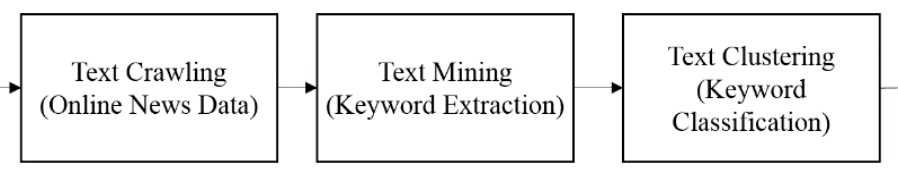

\section{Empirical Analysis}

(Topic Confirmation)

Figure 2. Research Procedure.

\subsection{Analysis Methods}

Text mining is used to find the rank, recognition, and generality of unstructured online text data using natural language processing and morphological analysis techniques [40,41]. This study analyzed the frequency of the words extracted from the news pages by using text mining. Semantic network analysis (SNA) is a methodology for showing the structure of relationships among various entities such as people, organizations, or communication concepts [42]. SNA was used to calculate the degree centrality measure, and convergent correlation (CONCOR) was applied to analyze the discourse. Degree centrality refers to the degree to which one node is located in the center of the network. Degree centrality is measured by the total amount of direct links with the other nodes [43]. CONCOR is the iterated calculation algorithm of the word correlation in the adjacency matrix [44]. With the CONCOR results, this study confirmed that barrier-related words exist online.

\section{Results}

\subsection{Keyword Frequency and Degree Centrality}

The frequency and degree centrality of the top 50 extracted words from text mining are shown in Table 4. Because TADA is a mobility service, "service" was the most frequent keyword. The "indictment" and "prosecution" keywords were second and fourth in frequency of appearance. This was a result of the Korean government's recent attempt to classify the TADA service as illegal. Interestingly, negative words frequently appeared. Exceptions included positive words such as "innovation". The degree centrality results did not differ significantly from the frequency results, but the word "call" ranked higher on the degree centrality list than on the frequency list. Because TADA is a mobility service to call a vehicle, the word "call" frequently appeared to explain TADA. 
Table 4. Keyword Frequency and Degree Centrality.

\begin{tabular}{|c|c|c|c|c|}
\hline \multirow{2}{*}{ Keyword } & \multicolumn{2}{|c|}{ Frequency } & \multicolumn{2}{|c|}{ Degree Centrality } \\
\hline & Count & Rank & Value & Rank \\
\hline Service & 815 & 1 & 0.042 & 2 \\
\hline Indictment & 467 & 2 & 0.033 & 6 \\
\hline Taxi & 442 & 3 & 0.050 & 1 \\
\hline Prosecution & 426 & 4 & 0.039 & 4 \\
\hline Representative & 344 & 5 & 0.025 & 10 \\
\hline Government & 341 & 6 & 0.042 & 3 \\
\hline Assembly & 326 & 7 & 0.026 & 9 \\
\hline Seoul & 292 & 8 & 0.022 & 13 \\
\hline Innovation & 289 & 9 & 0.027 & 8 \\
\hline Vehicle & 288 & 10 & 0.022 & 14 \\
\hline Illegality & 266 & 12 & 0.025 & 11 \\
\hline Call & 266 & 11 & 0.005 & 50 \\
\hline Dispute & 252 & 13 & 0.025 & 12 \\
\hline Taxi industry & 212 & 14 & 0.027 & 7 \\
\hline Platform & 201 & 15 & 0.017 & 19 \\
\hline Rally & 195 & 16 & 0.017 & 21 \\
\hline Reporter & 192 & 18 & 0.036 & 5 \\
\hline Mobility & 192 & 17 & 0.021 & 15 \\
\hline VCNC & 188 & 19 & 0.017 & 20 \\
\hline Car inspection & 180 & 20 & 0.017 & 22 \\
\hline Operation & 179 & 21 & 0.017 & 18 \\
\hline Van & 174 & 22 & 0.017 & 24 \\
\hline Coexistence & 161 & 23 & 0.008 & 42 \\
\hline Rental car & 156 & 24 & 0.021 & 16 \\
\hline Conflict & 153 & 25 & 0.017 & 23 \\
\hline Jaeuk Park & 151 & 26 & 0.009 & 40 \\
\hline Yeouido & 147 & 27 & 0.006 & 49 \\
\hline MOLIT & 142 & 28 & 0.021 & 17 \\
\hline Socar & 140 & 29 & 0.015 & 28 \\
\hline Blue House & 138 & 31 & 0.014 & 30 \\
\hline Car call & 138 & 30 & 0.007 & 48 \\
\hline MOJ & 137 & 32 & 0.016 & 26 \\
\hline Bill & 134 & 33 & 0.011 & 37 \\
\hline Stop & 127 & 34 & 0.011 & 36 \\
\hline TADA Out & 125 & 35 & 0.008 & 43 \\
\hline Expansion & 124 & 36 & 0.011 & 38 \\
\hline Plan & 119 & 37 & 0.013 & 32 \\
\hline TADA indictment & 112 & 38 & 0.012 & 35 \\
\hline Large scale & 109 & 39 & 0.008 & 45 \\
\hline SPTA & 108 & 40 & 0.013 & 31 \\
\hline Pressure & 107 & 41 & 0.009 & 39 \\
\hline Picture & 105 & 43 & 0.016 & 25 \\
\hline Minister & 105 & 42 & 0.012 & 34 \\
\hline Sharing & 103 & 44 & 0.007 & 46 \\
\hline Driver & 99 & 45 & 0.014 & 29 \\
\hline Jaeung Lee & 97 & 47 & 0.008 & 41 \\
\hline Violation & 97 & 46 & 0.007 & 47 \\
\hline Year's end & 96 & 48 & 0.008 & 44 \\
\hline Announcement & 89 & 49 & 0.015 & 27 \\
\hline Discussion & 89 & 50 & 0.013 & 33 \\
\hline
\end{tabular}

\subsection{CONCOR Analysis}

The result of visualizing the connection patterns and relationships within the network is shown in Figure 3. Figure 4 shows the results of the CONCOR analysis. The keyword network by CONCOR analysis was divided into eight word-groups. The first group of words concerned the introduction of TADA services. The second group consisted of the 
words "innovation" and "Seoul". The third group included words related to coexistence, and the fourth group included words used to discuss the existing bill. The remaining four groups consisted of negative keywords for TADA services, such as prosecution, illegality, conflict, and violations. The results of the CONCOR analysis show that there were many negative opinions online about TADA services. It also shows that there were various stakeholder groups involved, and that there was considerable debate among them. One group was struggling to secure the coexistence of TADA and the taxi industry and, conversely, there was also resistance to legally stopping TADA. It was also confirmed that there were groups trying to make political use of the TADA issue.

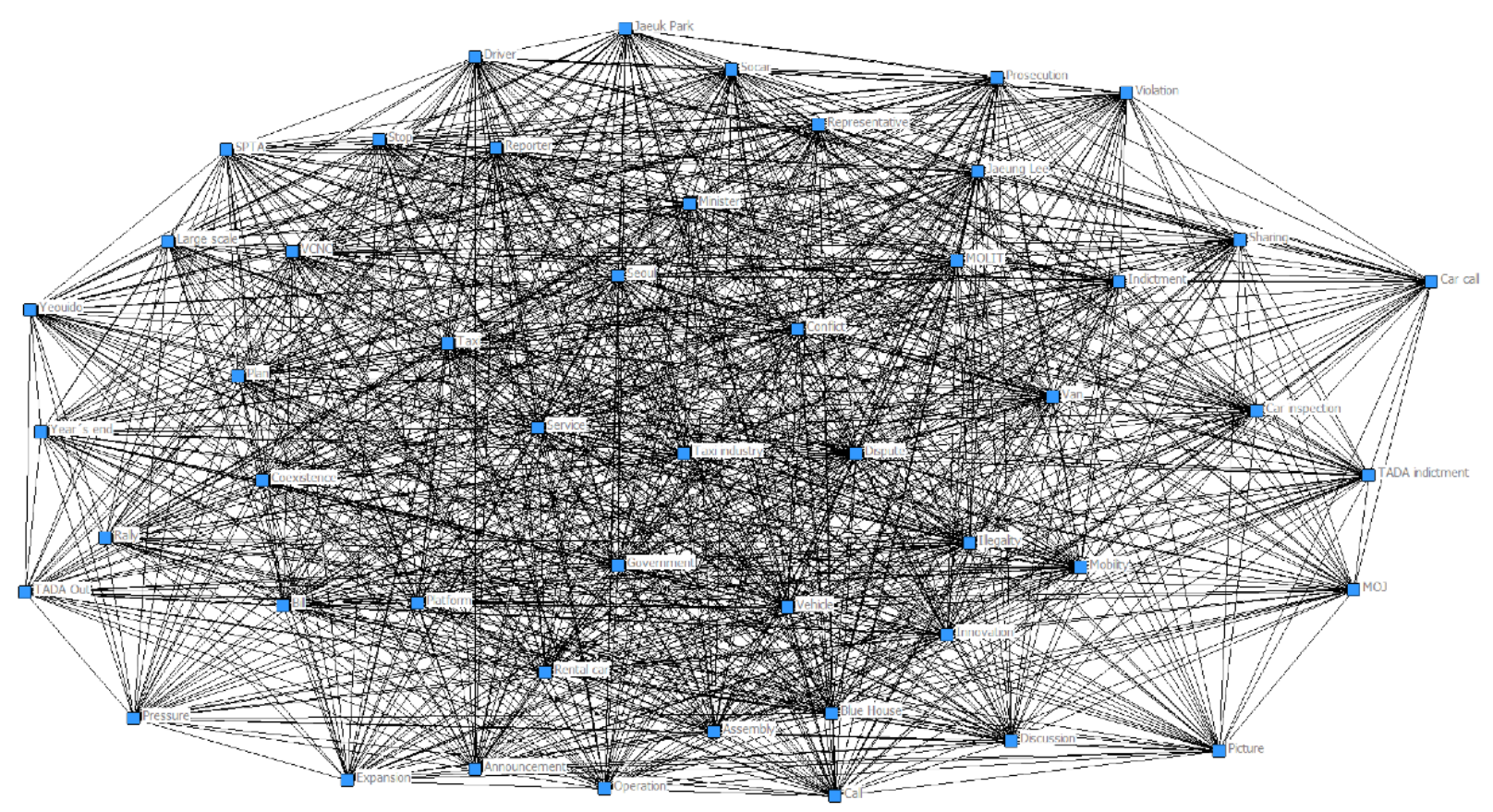

Figure 3. Network Visualization Result.

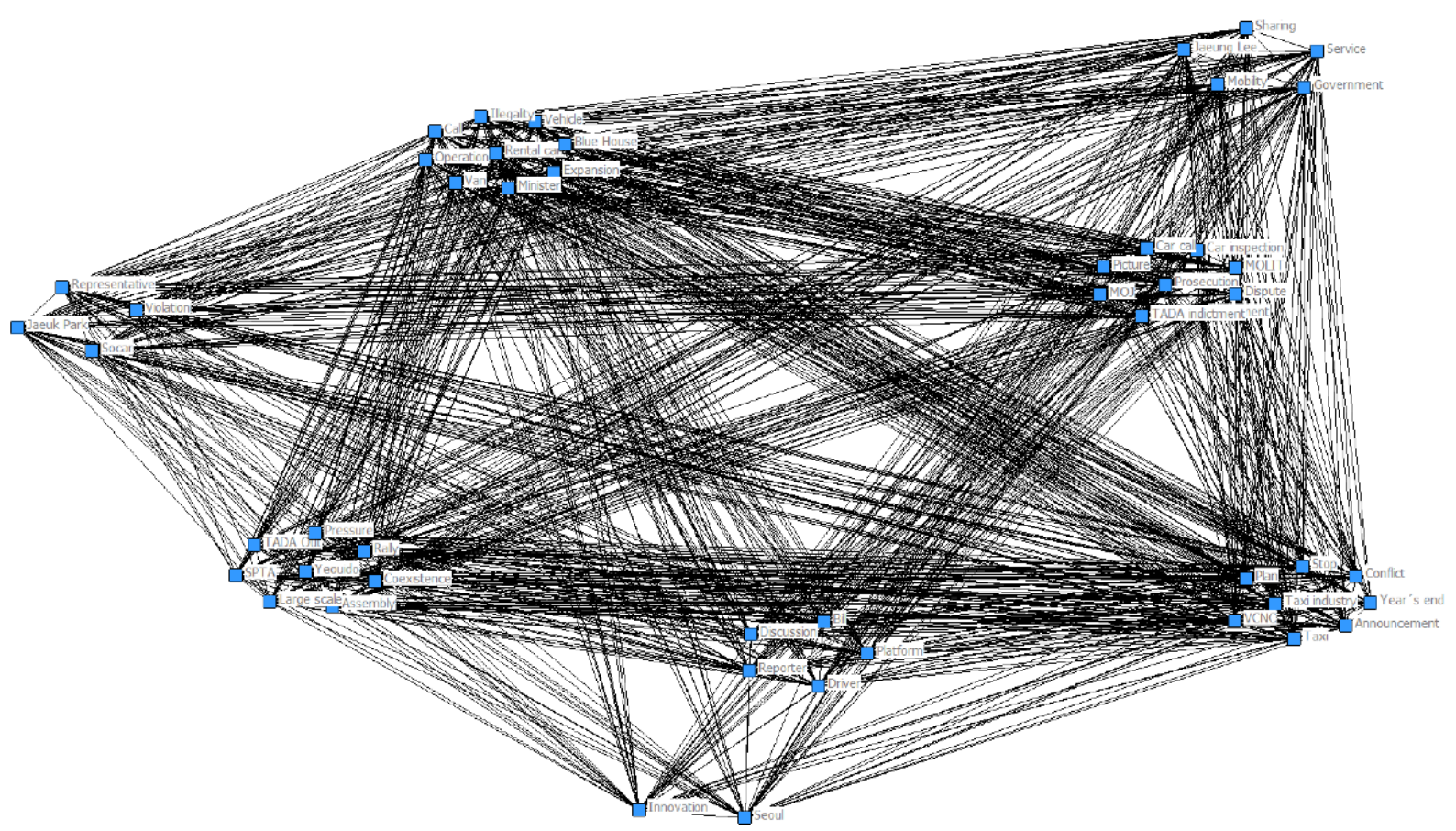

Figure 4. CONCOR Analysis Result. 


\section{Discussion}

\subsection{Findings}

The purpose of this study was to examine public awareness of innovative shared mobility services using text mining and big data analysis methods and to identify new innovation barriers that did not formerly exist. Conventionally, barriers to breakthrough technologies have been discussed as follows: personal resistance, economic resistance, socio-psychological resistance caused by pressure on individuals from social demands based on fixed traditions and social practices, and resistance due to the uncertainties of new technology.

The results of this study show that political, industrial, and legal issues might present a larger obstacle to the spread of shared mobility services compared to technological issues. Table 4 shows the Tada service being labeled with negative words, such as an indictment, dispute, or conflict. From the CONCOR analysis results (Figure 4), we can see that the online perception of the TADA service was divided into eight clusters, of which five clusters were related to TADA's illegality, conflict with the taxi industry, and debate with the government. These results show that the industrial or legal structures underlying a society can be a fundamental barrier to progress, even if technological advancements have triggered significant improvements in various aspects of our society. Through this TADA case study, we have confirmed that industrial and legal barriers do exist in Korea and that they stand in the way of technology adoption, especially when they are politicized. Thus, this study makes a theoretical contribution to the empirical analysis of a new type of technology diffusion barrier that had not been actively discussed before.

In this study, we were able to confirm through the analysis of online texts the coexistence of views favoring and opposing new innovation services. The keyword analysis showed that there were more people against the TADA service than for it. Most notably, as political groups intervened in the confrontation between those who were for the "TADA" service and those who were against it, the issue of social agreement over the introduction of breakthrough technologies was reduced to a conflict of political interests. There were many cases (confirmed through news reports and keywords analysis) that were analyzed as legal disputes between the opposing groups or legislative attempts to represent the interests of a group with politicians on their side. The political effect of the confrontation between groups over new technology is likely to increase as labor-intensive industrial structures contribute to the consolidation of the political barrier to the introduction of new and innovative technology. As a result, the passage of a bill against the ride-hailing service TADA has made the service illegal, and Korea's shared mobility service industry faces new resistance in the form of political and industrial structure barriers. This can be interpreted as political resistance with complicated interests intertwined, rather than as a traditional barrier to innovation such as those mentioned earlier. In the case of political resistance, it is also a factor in which positive effects can be expected to go through the process of social consensus. In the case of shared mobility in Korea, it was a negative factor in strengthening the confrontation between groups. This suggests that discussion on how to manage these barriers to the introduction of new technologies or services is necessary.

The case study of TADA showed that positive keywords such as "innovation" or "future" were mentioned less frequently than negative ones, such as "accusation", "illegal", or "outlaw". Along with big interest groups, it revealed a high political barrier with strong resistance to the introduction of new technologies. This study is significant as it examined and summarized the facts about barriers to the introduction of innovative technologies in the context of shared mobility services, including TADA, through keyword frequency and CONCOR analysis. It also identified political and industrial structural barriers in addition to previously recognized barriers. Political barriers hamper the process of holistic discussion on introducing new technology due to a focus on competing interests, and are highly likely to nullify the effect of the policies, including a regulatory sandbox that has been pursued in the drive for innovation. Regarding practical implications, this study found that governments need to sincerely predict and consider potential political 
or industrial structural resistance, as well as traditional barriers, to the establishment of scientific and technological strategies that explore breakthrough technologies, within the framework of the regulatory sandbox. In short, this shows that discussions of legal and social barriers should be more active in the discourse on diffusion of new innovative services.

Shared mobility services are used for the purposes of economics, convenience, lifestyle, and pollution prevention [45]. Therefore, such services are a viable option for those who value these. While both positive and negative perspectives exist, shared mobility services are necessary for those with difficulty owning a vehicle or in emergency situations [46]. Moreover, they are a viable alternative where public transportation services are scarce [47]. Despite these advantages, if innovative services cannot be sustained owing to the interests of certain groups, the pace of technological innovation will slow down. Considering the case of the Uber service, which is similar to TADA, it is clear that the role of government is critical in solving the problem. In San Francisco and Australia, where the government offered a balanced arbitration proposal, Uber services were able to successfully engage in the market. Therefore, when a conflict of benefits occurs between groups during innovation, the government should, as a proactive mediator, prioritize efforts to propose a balance of benefits for each. Innovative services can be collaboratively maintained when the government's role involves reducing conflict and providing appropriate conditions for negotiation. Therefore, support for continued government mediation and cooperation among stakeholders is required to prevent the recurrence of events such as TADA. These efforts will be the driving force to develop and sustain innovative solutions for the transportation industry in the future.

\subsection{Contributions}

In many countries around the world, various shared mobility services faced challenges in their quest for innovation. However, TADA's case is unique compared to those of other shared mobility platforms. Although both Uber and TADA offered paid transport services, Uber's case was clearly illegal in South Korea due to its use of private vehicles. Conversely, TADA operated within an area not yet regulated by law, or was in the blind spot of the law, and was therefore not considered illegal until relevant laws were amended. Nevertheless, the backlash and resistance to innovation from existing transport operators overturned the legality of TADA. Rather than highlighting the sociological phenomena of resistance to new technology and barriers to innovation, TADA's case sheds light on the more complex problem of legal and political resistance based on interests. As such, TADA's case requires in-depth study not only because it is different from existing cases on shared mobility, but also because it is ongoing and demands continued consideration and discussion. TADA was acquitted in its first trial, but the appeal is still pending as Korea's prosecutors are seeking a one-year prison sentence for TADA's CEOs. The fact that such a paradoxical situation occurred in South Korea-a country with highly advanced ICT infrastructureindicates the need to discuss innovation from a new, rather than traditional, perspective.

The first academic contribution of this study is that it empirically examined resistance to innovative services using big data-based text mining. While it is true that the study investigated a subject that is similar to existing literature on resistance to innovative services, it provided major academic value by applying a new methodology that offers an objective analysis of a topic that has only been discussed qualitatively. This study showed that big data analysis can be used as a new approach to explore innovation resistance factors. Second, through empirical analysis, this study confirmed that political, industrial, and legal factors can be stronger resistance factors to innovative services than technological factors. This empirical approach strongly suggests the need for a more comprehensive discussion of the factors behind resistance to innovative services on an academic level.

One of the practical contributions of this study is its analysis of TADA's innovation failure and subsequent implications for future industrial policies of countries embracing shared mobility services. It also shows that a misguided regulatory approach to innovative 
services may inhibit new industry creation and growth. When establishing laws and policies, a balanced approach is needed from the perspective of the entire industry, rather than prioritizing the interests of stakeholders. In addition, a comparison of the results of this study with cases from other countries shows the need for an organization in Korea that can professionally arbitrate disputes between traditional and innovative service providers. Cases such as that of TADA may continue to occur in the future, and resistance and disputes are bound to arise accordingly. Once innovative services overcome this resistance, they will become successful innovations. Innovative ideas are institutionalized mainly through bottom-up decision making, and as they pass through the institutionalization stage and into dissemination, various mediation systems are needed to reconcile conflicts. Innovation is generalized through this process, and the government must play a role in mediating disputes arising from resistance to innovation.

\subsection{Limitations and Further Study}

As with any study, potential limitations for the research conducted here should be acknowledged. First, news data collected over a short period of time were analyzed. In addition, an in-depth examination of the effect of traditional barriers on the diffusion of breakthrough technologies, and how such barriers can be overcome, was not the main focus of this work. It is therefore necessary to engage in discussion and conduct further research to better understand the complex, underlying, and interrelated issues for any proposed solution to achieve generalizability. This study makes a theoretical contribution as it empirically confirms that new barriers exist for the innovation process; however, a significant drawback is that in-depth discussions on potential solutions were limited. Thus, further empirical research is required for effective solutions to emerge in terms of solving the existing barriers.

With the advent of the Fourth Industrial Revolution, technological development is accelerating, and what used to be impossible due to technological limitations is gradually becoming possible. However, this development is limited to the technological dimension and has struggled to address personal habits or social barriers to help the new technology take root. New technologies that are not successfully commercialized lead to low efficiency and profitability, and are likely to die out no matter how promising they might have seemed at first. Therefore, it is crucial to continue research on how to break down social barriers to technology diffusion for the lasting development of science and technology as well as the prosperity of humankind.

Author Contributions: Conceptualization, S.K. and H.L.; methodology, H.L.; validation, S.-W.S.; formal analysis, H.L.; writing — original draft preparation, S.K.; writing—review and editing, H.L. and S.-W.S. All authors have read and agreed to the published version of the manuscript.

Funding: This work was supported by the Ministry of Education of Korea and the National Research Foundation of Korea (NRF-2019S1A3A2098438); and by the growth support project for industrial innovation talent of MOTIE (P0008703).

Institutional Review Board Statement: Not applicable.

Informed Consent Statement: Not applicable.

Data Availability Statement: Not applicable.

Conflicts of Interest: The authors declare no conflict of interest.

\section{References}

1. Torre-Bastida, A.I.; Del Ser, J.; Laña, I.; Ilardia, M.; Bilbao, M.N.; Campos-Cordobés, S. Big Data for transportation and mobility: Recent advances, trends and challenges. IET Intell. Transp. Syst. 2018, 12, 742-755. [CrossRef]

2. Miyata, H. Digital Transformation of Automobile and Mobility Service. In Proceedings of the 2018 International Conference on Field-Programmable Technology (FPT), Naha, Japan, 10-14 December 2018; pp. 1-5.

3. Kim, J.-H.; Kim, S.-I. A study on User Experience of Mobility Platform Service-Focused on kakao Taxi and Tada. J. Digit. Converg. 2019, 17, 351-357. 
4. Ji-hye, J. No Startups in Korea if Tada is Illegal. The Korea Times, 14 November 2019. Available online: https:/ /www.koreatimes. co.kr/www/tech/2019/11/133_278168.html (accessed on 7 April 2021).

5. Clewlow, R.R.; Mishra, G.S. Disruptive Transportation: The Adoption, Utilization, and Impacts of Ride-Hailing in the United States; UC Davis: Davis, CA, USA, 2017.

6. Xu, H.; Yu, W.; Griffith, D.; Golmie, N. A survey on industrial Internet of Things: A cyber-physical systems perspective. IEEE Access 2018, 6, 78238-78259. [CrossRef]

7. Liberato, P.; Alen, E.; Liberato, D. Smart tourism destination triggers consumer experience: The case of Porto. Eur. J. Manag. Bus. Econ. 2018, 27, 6-25. [CrossRef]

8. Pradhan, M.K.; Oh, J.; Lee, H. Understanding travelers' behavior for sustainable smart tourism: A technology readiness perspective. Sustainability 2018, 10, 4259. [CrossRef]

9. Lessig, L. Remix: Making Art and Commerce Thrive in the Hybrid Economy; Penguin: New York, NY, USA, 2008.

10. Kim, H.-J.; Park, J.-W.; Jo, D.-H. An Empirical Study on Success Factors of Sharing Economy Service. J. Korea Contents Assoc. 2016, 16, 214-229. [CrossRef]

11. Pouri, M.J.; Hilty, L.M. Conceptualizing the digital sharing economy in the context of sustainability. Sustainability 2018, 10, 4453. [CrossRef]

12. Park, D.; Kim, Y.; Lee, Y.; Ryu, D. Sharing Economy Platforms and Tying. Korean Manag. Rev. 2020, 49, 499-520. [CrossRef]

13. Botsman, R.; Rogers, R. Whats Mine Is Yours: The Rise of Collaborative Consumption; Harper Business: New York, NY, USA; Collins: London, UK, 2010.

14. Rahman, M.A.; Rashid, M.M.; Hossain, M.S.; Hassanain, E.; Alhamid, M.F.; Guizani, M. Blockchain and IoT-based cognitive edge framework for sharing economy services in a smart city. IEEE Access 2019, 7, 18611-18621. [CrossRef]

15. Rigby, M.; Winter, S.; Krüger, A. A continuous representation of ad hoc ridesharing potential. IEEE Trans. Intell. Transp. Syst. 2016, 17, 2832-2842. [CrossRef]

16. Ram, S.; Sheth, J.N. Consumer Resistance to Innovations: The Marketing Problem and its Solutions. J. Consum. Mark. 1989, 6, 5-14. [CrossRef]

17. Sheth, J.N.; Stellner, W.H. Psychology of Innovation Resistance: The Less Developed Concept (LDC) in Diffusion Research; University of Illinois: Champaign, IL, USA, 1979.

18. Ram, S. A model of innovation resistance. Acr. N. Am. Adv. 1987, 14, 208-212.

19. Ellen, P.S.; Bearden, W.O.; Sharma, S. Resistance to technological innovations: An examination of the role of self-efficacy and performance satisfaction. J. Acad. Mark. Sci. 1991, 19, 297-307. [CrossRef]

20. Holak, S.L.; Lehmann, D.R. Purchase intentions and the dimensions of innovation: An exploratory model. J. Prod. Innov. Manag. Int. Publ. Prod. Dev. Manag. Assoc. 1990, 7, 59-73. [CrossRef]

21. Laukkanen, P.; Sinkkonen, S.; Laukkanen, T. Consumer resistance to internet banking: Postponers, opponents and rejectors. Int. J. Bank Mark. 2008, 26, 440-455. [CrossRef]

22. Han, H.; Hsu, L.-T.J.; Sheu, C. Application of the theory of planned behavior to green hotel choice: Testing the effect of environmental friendly activities. Tour. Manag. 2010, 31, 325-334. [CrossRef]

23. Kim, H.-W.; Kankanhalli, A. Investigating user resistance to information systems implementation: A status quo bias perspective. Mis Q. 2009, 33, 567-582. [CrossRef]

24. Eckhardt, A.; Laumer, S.; Weitzel, T. Who influences whom? Analyzing workplace referents' social influence on IT adoption and non-adoption. J. Inf. Technol. 2009, 24, 11-24. [CrossRef]

25. Molesworth, M.; Suortti, J.P. Buying cars online: The adoption of the web for high-involvement, high-cost purchases. J. Consum. Behav. Int. Res. Rev. 2002, 2, 155-168. [CrossRef]

26. Kleijnen, M.; Lee, N.; Wetzels, M. An exploration of consumer resistance to innovation and its antecedents. J. Econ. Psychol. 2009, 30, 344-357. [CrossRef]

27. Barabino, B.; Salis, S.; Assorgia, A. Application of mobility management: A web structure for the optimisation of the mobility of working staff of big companies. IET Intell. Transp. Syst. 2012, 6, 87-95. [CrossRef]

28. Kahneman, D.; Knetsch, J.L.; Thaler, R.H. Anomalies: The endowment effect, loss aversion, and status quo bias. J. Econ. Perspect. 1991, 5, 193-206. [CrossRef]

29. Heidenreich, S.; Spieth, P. Why innovations fail-The case of passive and active innovation resistance. Int. J. Innov. Manag. 2013, 17, 1350021. [CrossRef]

30. van der Geest, L.; Heuts, L. Barriers to innovation. In Micro-Foundations for Innovation Policy; Nooteboom, B., Stam, E., Eds.; Amsterdam University Press: The Hague, The Netherlands, 2008; pp. 173-198.

31. Jiang, J.J.; Muhanna, W.A.; Klein, G. User resistance and strategies for promoting acceptance across system types. Inf. Manag. 2000, 37, 25-36. [CrossRef]

32. Hirschheim, R.; Newman, M. Information systems and user resistance: Theory and practice. Comput. J. 1988, 31, 398-408. [CrossRef]

33. Holverson, C. Overcoming Barriers to Adoption for Innovations in Policy: Reflections from the Innovation Toolkit. Innov. Technol. Gov. Glob. 2017, 11, 64-79. [CrossRef] 
34. Kim, S.; Park, H.; Lee, H. The Diffusion Barriers of AI Mobility Service: The Case of TADA. In Proceedings of the 2020 International Conference on Artificial Intelligence in Information and Communication (ICAIIC), Fukuoka, Japan, 19-21 February 2020; pp. 666-670.

35. Jun-suk, Y. Mobility Startups Protest Government's Ride-Sharing Reform Plan. The Korea Herald, 17 July 2019. Available online: http:/ / www.koreaherald.com/view.php?ud=20190717000730(accessed on 7 April 2021).

36. Kang, H.M. Controversy Deepens over Accepting Ride-sharing Services or Protecting the Taxi Industr. The Korea Bizwire, 29 May 2019. Available online: http:/ / koreabizwire.com/controversy-deepens-over-accepting-ride-sharing-services-or-protectingthe-taxi-industry/138113,(accessed on 7 April 2021).

37. Song, K. Taxi Drivers Go to War against Tada Van-Hailing App. Korea JoongAng Daily, 19 February 2019. Available online: https:/ / koreajoongangdaily.joins.com/news/article/article.aspx?aid=3059627(accessed on 7 April 2021).

38. Ji-hye, J. Taxi Drivers up in Arms against Tada Verdict. The Korea Times, 20 February 2020. Available online: https://www. koreatimes.co.kr/www/tech/2020/02/133_283786.html(accessed on 7 April 2021).

39. Byung-yeul, B. Tada Forced to End Van-Hailing Service in April. The Korea Times, 11 March 2020. Available online: https: //www.koreatimes.co.kr/www/tech/2020/03/133_286018.html(accessed on 7 April 2021).

40. Meyer, D.; Hornik, K.; Feinerer, I. Text mining infrastructure in R. J. Stat. Softw. 2008, 25, 1-54.

41. Shi, L.; Jianping, C.; Jie, X. Prospecting information extraction by text mining based on convolutional neural networks-a case study of the Lala copper deposit, China. IEEE Access 2018, 6, 52286-52297. [CrossRef]

42. Ruiz, J.B.; Barnett, G.A. Exploring the presentation of HPV information online: A semantic network analysis of websites. Vaccine 2015, 33, 3354-3359. [CrossRef] [PubMed]

43. Zhang, J.; Luo, Y. Degree centrality, betweenness centrality, and closeness centrality in social network. In Proceedings of the 2017 2nd International Conference on Modelling, Simulation and Applied Mathematics (MSAM2017), Bangkok, Thailand, 26-27 March 2017; pp. 300-303.

44. Richards, W.; Seary, A. Eigen analysis of networks. J. Soc. Struct. 2000, 1, 1-17.

45. Machado, C.A.S.; de Salles Hue, N.P.M.; Berssaneti, F.T.; Quintanilha, J.A. An overview of shared mobility. Sustainability 2018, 10, 4342. [CrossRef]

46. Li, M.; Xu, J.; Liu, X.; Sun, C.; Duan, Z. Use of shared-mobility services to accomplish emergency evacuation in urban areas via reduction in intermediate trips-Case study in Xi'an, China. Sustainability 2018, 10, 4862. [CrossRef]

47. Krueger, R.; Rashidi, T.H.; Rose, J.M. Preferences for shared autonomous vehicles. Transp. Res. Part C Emerg. Technol. 2016, 69, 343-355. [CrossRef] 